\title{
The Effectiveness of Mometasone Spray and Triamcinolone Acetonide Gel in Preventing Sore Throat, Cough, and Hoarse after Intubation
}

\author{
Zentika. I. Fajri ${ }^{1}$, Fredi Heru Irwanto ${ }^{2 *}$, A Miarta ${ }^{3}$, Theodorus ${ }^{3}$ \\ ${ }^{1}$ Resident of Department of Anesthesiology and Intensive Therapy, Faculty of Medicine Universitas Sriwijaya, \\ Mohammad Hoesin Hospital, Palembang, Indonesia \\ ${ }^{2}$ Consultant of Department of Anesthesiology and Intensive Therapy, Faculty of Medicine Universitas Sriwijaya, \\ Mohammad Hoesin Hospital, Palembang, Indonesia \\ ${ }^{3}$ Department of Pharmacology, Faculty of Medicine Universitas Sriwijaya, Palembang, Indonesia
}

\section{*Corresponding author: \\ Fredi Heru Irwanto \\ Consultant of Department of \\ Anesthesiology and Intensive \\ Therapy, Faculty of Medicine \\ Universitas Sriwijaya, \\ Mohammad Hoesin Hospital, \\ Palembang, Indonesia}

Email:

fhaeroo.dr@gmail.com

https://doi.org/10.37275/jacr.v1i2.144

\begin{abstract}
Background: Endotracheal intubation is a procedure performed by inserting an endotracheal tube into the airway. With endotracheal intubation, there can be several complications ranging from mild to severe. Sore throat, coughing, and hoarseness were several endotracheal intbation complications. From several studies, it was found that the incidence of POST was 21-65\%. This study aimedto determine the efficacy between $0.1 \%$ triamcinolone acetonide gel and $100 \mathrm{mcg}$ mometasone spray in reducing sore throat, cough, and hoarseness due to endotracheal intubation.

Method: A Randomized Controlled Trial, Open-Label was carried out on patients undergoing endotracheal intubation with general anesthesia in RSMH operating room from September 2020 - November 2020. Seventy-two study subjects met the inclusion criteria and were divided into two groups, namely the triamcinolone acetonide gel group, and the mometasone spray group. Analyzing data was SPSS version 23.

Result: There were no difference between age, sex, ASA PS classification, and length of operation between the two groups ( $\mathrm{p}>0.05)$. Mometasone spray $100 \mathrm{mcg}$ and triamcinolone acetonide gel $0.1 \%$ had the same effectiveness to reduce endotracheal intubation such as sore throat, cough, and hoarseness within 24 hours of endotracheal intubation ( $p>0.05)$. There was a significant difference in the incidence of sore throatbetween two groups in the firsthour $(p=0.039)$.

Conclusion: There was no statistically significant difference between the efficiency of mometasone spray $100 \mathrm{mcg}$ and triamcinolone acetonide gel $0.1 \%$ on a sore throat, cough, and hoarseness within 24 hours of endotracheal intubation $(\mathrm{p}>0.05)$.
\end{abstract}

Keywords: Mometasone Spray $100 \mathrm{Mcg}$, Triamcinolone Acetonide Gel 0.1\%, Randomized Controlled Trial. 


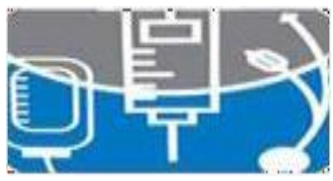

\section{Journal of Anesthesiology \& \\ Clinical Research}

\section{Introduction}

Endotracheal intubation is a procedure performed by inserting an endotracheal tube into the airway. Using endotracheal intubation can be several mild to severe complications. Sore throat, coughing, and hoarseness were several endotracheal intbation complications. ${ }^{1}$ In Orandi's 2013 study, the prevalence of cough, sore throat, and hoarseness was $18 \%$ - 65\%, and in Narimani et al's study, it was 14.4-50\%.,3 Meanwhile, in 2017, Wendy's showed the prevalence of sore throat, cough, and hoarseness in RSMH was $17.8 \%-21.4 \% .{ }^{4}$ Pain throat, hoarseness, coughing, and nausea were the most common complication after endotracheal intubation. Although sore throat, cough, and hoarseness do not cause serious complications, they make the patient stressed and have a bad memory after the intubation procedure. Risk factors for sore throat, cough, and hoarseness are female gender, hi story of smoking, time of extubation, history of cough, duration of anesthesia, history of ulcers, size of Endotracheal Tube (ETT), dentures, ETT cuff pressure,

Main complaints that often occur after endotracheal intubation are cough, sore throat, and hoarseness after surgery. The causes of sore throat, coughing and hoarseness make irritation and traumato the airway. The ETT lubrication drug that has been tested and researched for its ability to reduce the incidence of sore throat, cough and hoarseness has mixed success rates. ETT lubrication is useful for reducing mucosal damage by facilitating the entry of ETT into the trachea. Topical steroids as lubrication drugs are a good choice for reducing the incidence of cough, sore throat, and hoarseness because they reduce thracea mucosal irritation and inflammation of which may be the main cause of sore throat, cough, and hoarseness.

Triamcinolone acetonide is a corticosteroid that has anti-inflammatory, anti-pruritic, and vasoconstrictive effects. Anti-inflammatory mechanism in topical steroids is not clear yet. Corticosteroids induce phospholipase A2 inhibitor proteins called lipocortins. This protein functions to control the production of inflammatory mediators (prostaglandin and leukotrienes) by inhibiting its precursor, arachidonic acid. Arachidonic acid is released from the phospholipid membrane by phospholipase A2. In the research, Ayoub et al stated that Triamcinolone acetonide gel $0.1 \%$ only has one-fifth of the glucocorticoid activity of betamethasone with a dose of $0.1 \%$ triamcinolone acetonide gel equivalent to $0.4 \mathrm{mg}$ of prednisone. The study found that the incidence endotracheal complication (sore throat, cough, and hoarseness) was $19,4 \%$ lower than other studies using betamethasone ${ }^{6,7}$

Mometasone is a topical glucocorticosteroid with local anti-inflammatory effects at a systemically 


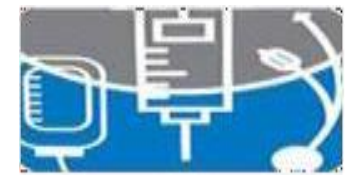

\section{Journal of Anesthesiology \& \\ Clinical Research}

inactive dose. Mometasone has antiallergic and anti-inflammatory effects because mometasone can inhibit the release of mediators from allergic reactions. In cell culture, mometasone shows high potency in inhibiting the synthesis and release of IL-1, IL-5, IL-6, and TNF $\alpha$. Besides mometasone inhibits leukotriene production, mometasone is a strong inhibitor of the production of Th2, IL-4, and IL-5 cytokines, from CD4

$+\mathrm{T}$ cells. Mometasone spray is a corticosteroid with moderate potency available in the form of a nasal spray which is effective as a therapy for allergic rhinitis. The study was conducted by Arunchai et al. of 42 American Society of Anesthesiologists (ASA) physical status of 1 and 2 general anesthesized patients. They concluded that the administration of mometasone spray reduced post- intubation sore throat. Wirdiyana et al also stated that mometasone spray is effective in postintubation complications such as cough and sore throat. ${ }^{8,9}$

The analgesic and anti-inflammatory potential of $0.1 \%$ triamcinolone acetonide gel and antiinflammatory potential in $100 \mathrm{mcg}$ mometasone spray, the administration of $0.1 \%$ triamcinolone acetonide gel, and 100 mcg mometasone spray can be used as lubrication in ETT before endotracheal intubation and is expected to prevent pain events. throat, cough, and hoarseness after intubation. Also, the use of triamcinolone acetonide gel $0.1 \%$ and mometasone furoate spray $100 \mathrm{mcg}$ are relati vely safe to use, minimal side effects, well-tolerated, and available in the operating room so that it is expected to reduce the incidence of cough, sore throat, and hoarseness. This study aims to analyze the effectiveness ofmometasone spray $100 \mathrm{mcg}$ with triamcinolone acetonide gel $0.1 \%$ in reducing sore throat, cough, and hoarseness after endotracheal intubation.

\section{Method}

This study is a randomized clinical trial with an open-ended companion in a patient undergoing surgery under general anesthesia with the endotracheal intubation technique performed in the operating room of Dr. Mohammad Hoesin hospital, from September 2020-November 2020 or until the number of samples is met. The study was conducted after the approval of the Health Research Ethics Committee.

All patients who underwent elective surgery undergoing general anesthesia with endotracheal intubation technique at RSUP Dr. Mohammad Hoesin Palembang who met the inclusion criteria will be the research sample. The inclusion criteria included male and female patients who were going to undergo planned surgery under general anesthesia with endotracheal intubation in the supine position, age 18-65 years, ASA I-II status, underwent anesthesia for 30-240 minutes, and willingness to follow. research and 


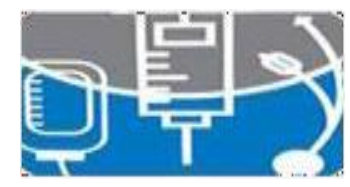

\section{Journal of Anesthesiology \& \\ Clinical Research}

sign informed consent.

Patients who underwent surgery on the head, neck and airways, patients who had nasal intubation, patients who required NGT during the first 24 hours postoperatively, patients who had difficulty intubating and induced fast or Sellick Maneuver, patients with a history of hoarseness and asthma before surgery, mallampati grade $>2$, allergies to the drugs to be tested, a history of using NSAIDs before surgery, patients suffering from upper respiratory tract infections 1 week before, patients taking steroids, patients using oral packing Patients with more than 2 attempts to intubate, bleeding during intubation, which are known directly at tintubation or after extubation, patients who require mechanical ventilation after surgery, anesthesia time is more than 4 hours, patients who are allergic to drugs drugs used during surgery, patients who experience shock and massive bleeding during the operation, Patients referred or transferred from another hospital's ICU, patients with active bleeding, malignancy, acute coronary syndrome, have a history of platelet abnormalities, treated for less than 24 hours, re-admission to the ICU within the same treatment period and incomplete medical record data will be excluded. in research.

The research samples were elective surgery patients with general anesthesia at Mohammad Hoesin hospital who was matched based on age, sex, and duration of operation with a minimum number of samples for each group is 33 people or 66 people for both groups. Adding 10\% to the likelihood of exclusion from the study would take 72 people in all for both groups. The sample size for each group is 33 people or 66 people for both groups. Adding $10 \%$ to the likelihood of exclusion from the study would take 72 people in all for both groups.

Data retrieval is carried out matching based on age, gender, and length of operation in elective surgery patients with general anesthesia at dr. Mohammad Hoesin Palembang. This study consisted of 3 variables, namely: independent variables (sore throat, cough, and hoarseness), the dependent variable $(0.1 \%$ triamcinolone acetonide gel lubrication bat and $100 \mathrm{mcg}$ Mometasone spray), universal variables (age, gender, length of time). operation).

The data will be processed and analyzed by computer, using the SPSS program (StatisticalPackage for Social Science). All data that has been collected is entered in the master table, and after completion, it is processed and displayed in tabulated and/or graphical form. Continuous variables were analyzed using the T-test, while dichotomic variables were analyzed using the Chi-Square test. The Mc Nemar test was used to analyze the effectiveness by using a matching sample. All data analysis used SPSSver 23. 


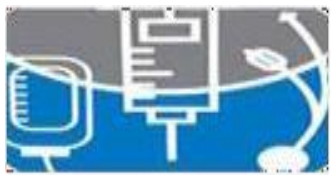

\section{Journal of Anesthesiology\& \\ Clinical Research}

\section{Result}

Clinical testing was carried out by comparing 2 groups of the study population as many as 72 elective surgery patients with general anesthesia and endotracheal intubation technique that met the inclusion criteria and did not include the exclusion criteria. There were 36 patients in the Triamcinolone Gel $0.1 \%$ group and 36 patients in the 100 mcg mometasone spray group who were the subject of the study. The study was held from October to December 2020.

Based on age, the mean age of the $0.1 \%$ triamcinolone acetonide gel group was $45.81 \pm 17.04$ years and the mean age of the $100 \mathrm{mcg}$ mometasone spray group was $41.67 \pm 14.05$ years (Table 1 ). With the chi-square test, the p-value was $0.410(\mathrm{p}>0.05)$, which means that there was no significant difference in age between the two groups.

The mean duration of operation of the $0.1 \%$ triamcinolone acetonide gel group was $113.33 \pm 17.73$ minutes and the average operating time of the $100 \mathrm{mcg}$ mometasone spray group was $110.42 \pm 21.26$ minutes. With the chi-square test, the p-value was $0.884(\mathrm{p}>0.05)$, which means that there was no significant difference in the length of operation between the two groups.

Table 1. Characteristics of research subjects

\begin{tabular}{lccc}
\hline \multicolumn{1}{c}{ Variable } & $\begin{array}{c}\text { Triamcinolone gel } 0.1 \% \\
\text { group } \\
(\mathrm{n}=36 \text { subjects })\end{array}$ & $\begin{array}{c}\text { Mometasone Spray } \\
\text { group 100 mcg } \\
(\mathrm{n}=36 \text { subjects })\end{array}$ & $\mathrm{p}$ \\
\hline $\begin{array}{c}\text { Age (years), } \\
\text { mean + SD }\end{array}$ & $45.81 \pm 17.04$ & $41.67 \pm 14.05$ & $0.410 *$ \\
$\begin{array}{c}\text { Operation time (minutes), } \\
\text { mean + SD }\end{array}$ & $113.33 \pm 17.73$ & $110.42 \pm 21.26$ & $0.884 * *$ \\
$\begin{array}{l}\text { Gender, n }(\%) \\
\text { Man } \\
\text { Women }\end{array}$ & $22(61.1 \%)$ & $11(30.6 \%)$ & $0.458 * *$ \\
ASA, n $(\%)$ & $14(38.9 \%)$ & $25(69.4 \%)$ & \\
1 & & $24(66.7 \%)$ & $0.096 * *$ \\
2 & $17(47.2 \%)$ & $12(33.3 \%)$ & \\
\hline
\end{tabular}

Chi Square test, $\mathrm{p}=0.05 ; \mathrm{p}$ is significant if $\mathrm{p}<0.05$

The mean duration of operation of the $0.1 \%$ triamcinolone acetonide gel group was $113.33 \pm 17.73$ minutes and the average operating time of the $100 \mathrm{mcg}$ mometasone spray group was $110.42 \pm 21.26$ 


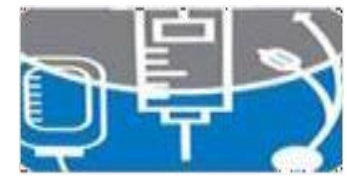

\section{Journal of Anesthesiology \& \\ Clinical Research}

minutes. No difference in the length of operation between the two groups $(\mathrm{p}=0.884)$.

Based on the sex of the triamcinolone acetonide gel group 0.1\% 22 men (61.1\%) and 14 women (38.9\%), the $100 \mathrm{mcg}$ mometasone spray group found 11 male patients $(30,6 \%)$ and women as many as 25 people $(60.4 \%)$. There was no significant difference between the sexes of the two groups $(\mathrm{p}=0.458)$.

Based on the ASA group of $0.1 \%$ triamcinolone acetonide gel, 17 patients with ASA 1 were found (47.2\%) and 19 people with ASA $2(52.8 \%)$ while the 100 mcg mometasone spray group found 24 patients with ASA 1. people (66.7\%) and ASA 2 as many as 12 people (33.3\%). ASA physical status were the same between the two groups $(\mathrm{p}=0.096)$.

Furthermore, the effectiveness of triamcinolone acetonide was compared $0.1 \%$ gel and $100 \mathrm{mcg}$ mometasone spray against sore throat, cough, and hoarseness in 24 hours after endotracheal intubation. The incidence of sore throat, cough, and hoarseness of the two groups was examined at 24 hours, then a statistical test was performed to compare the incidence between the two groups using the Mc Nemar test. From the statistical test triamcinolone acetonide gel group and $100 \mathrm{mcg}$ mometasone spray had no endotracheal intubation complication differences $(\mathrm{p}$-value $=1,000)$. (Table 2$)$

Table 2. Comparison of the effectiveness of triamcinoloneacetonide gel $0.1 \%$ and mometasone spray 100 $\operatorname{mcg}$

\begin{tabular}{lccc}
\hline & \multicolumn{2}{c}{ After 24 hours of administration } & \\
\cline { 2 - 3 } & $\begin{array}{l}\text { Triamcinolone gel 0.1\% } \\
\text { group }(\mathrm{n}=36 \text { subjects) }\end{array}$ & $\begin{array}{c}\text { Mometasone Spray group } \\
100 \text { mcg }(\mathrm{n}=36 \text { subjects })\end{array}$ & \\
\hline $\begin{array}{l}\text { Sore throat } \\
\text { Yes }\end{array}$ & $0(0 \%)$ & $0(0 \%)$ & 1.000 \\
$\quad$ Not & $36(100 \%)$ & $36(100 \%)$ & \\
$\begin{array}{l}\text { Cough } \\
\text { Yes }\end{array}$ & $0(0 \%)$ & $0(0 \%)$ & 1.000 \\
$\quad$ Not & $36(100 \%)$ & $36(100 \%)$ & \\
Hoarseness & $0(0 \%)$ & $0(0 \%)$ & 1.000 \\
Yes & $36(100 \%)$ & $36(100 \%)$ & \\
Not & 36 & 36 & \\
Total & & & \\
\hline
\end{tabular}

* Mc Nemar test, the p-value is significant if $<0.05$

No sore throat difference at 0,6 and 24 hours, the incidence of sore throat after endotracheal intubation was obtained by statistical analysis of the probability value of sore throat at 0,6 , and 24 hours, 


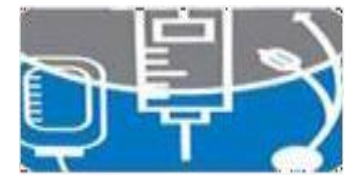

\section{Journal of Anesthesiology \& \\ ClinicalResearch}

respectively $0.543 ; 0.643$ and 1.000 ( $\mathrm{p}>0.05)$. Meanwhile, the probability value of sore throat on the 1 st hour was 0.039 ( $\mathrm{p}<0.05)$, so it can be concluded that there was a significant difference in the sore throat at the $1^{\text {st }}$ hour between the two groups. (Table 3)

Table 3 Degree of Sore Throat

\begin{tabular}{|c|c|c|c|}
\hline $\begin{array}{c}\text { The degree of sore } \\
\text { throat }\end{array}$ & $\begin{array}{c}\text { Triamcinolone gel } \\
0.1 \% \text { group } \\
(\mathrm{n}=36 \text { subjects })\end{array}$ & $\begin{array}{c}\text { Mometasone Spray } \\
\text { group } 100 \mathrm{mcg} \\
(\mathrm{n}=36 \text { subjects })\end{array}$ & $\mathrm{P}$ \\
\hline \multicolumn{4}{|l|}{ Hour 0} \\
\hline No pain & $22(61.1 \%)$ & $26(72.2 \%)$ & \multirow{4}{*}{0.543} \\
\hline Mild pain & $10(27.8 \%)$ & $8(22.2 \%)$ & \\
\hline Moderate pain & $4(11.1 \%)$ & $2(5.6 \%)$ & \\
\hline Severe pain & $0(0 \%)$ & $0(0 \%)$ & \\
\hline \multicolumn{4}{|l|}{ Hour 1} \\
\hline No pain & $24(66.7 \%)$ & $32(88.9 \%)$ & \multirow{4}{*}{0.035} \\
\hline Mild pain & $10(27.8 \%)$ & $2(5.6 \%)$ & \\
\hline Moderate pain & $2(5.6 \%)$ & $2(5.6 \%)$ & \\
\hline Severe pain & $0(0 \%)$ & $0(0 \%)$ & \\
\hline \multicolumn{4}{|l|}{ Hour 6} \\
\hline No pain & $33(91.7 \%)$ & $34(94.4 \%)$ & \multirow{4}{*}{0.643} \\
\hline Mild pain & $3(8.3 \%)$ & $2(5.6 \%)$ & \\
\hline Moderate pain & $0(0 \%)$ & $0(0 \%)$ & \\
\hline Severe pain & $0(0 \%)$ & $0(0 \%)$ & \\
\hline \multicolumn{4}{|l|}{ Hour 24} \\
\hline No pain & $36(100 \%)$ & $36(100 \%)$ & \multirow{4}{*}{1.000} \\
\hline Mild pain & $0(0 \%)$ & $0(0 \%)$ & \\
\hline Moderate pain & $0(0 \%)$ & $0(0 \%)$ & \\
\hline Severe pain & $0(0 \%)$ & $0(0 \%)$ & \\
\hline
\end{tabular}

* Chi Square test, Pearson chi square; $\mathrm{p}$ is significant if $\mathrm{p}<0.05$

The incidence of cough after endotracheal intubation was obtained from statistical analysis of cough probability values at $0,1,6$, and 24 hours, respectively $0.836 ; 0.556 ; 0.555$; and 1.000 ( $\mathrm{p}>0.05)$ so it can be concluded both groups had similar efficacy to reduce the incidence of cough at $0,1,6$, and 24 hours between the two groups statistically (Table 4). 


\section{Journal of Anesthesiology \& \\ ClinicalResearch}

Table 4 Degree of cough

\begin{tabular}{|c|c|c|c|}
\hline Degree of cough & $\begin{array}{l}\text { Triamcinolone gel } 0.1 \% \\
\text { group }(n=36 \text { subjects) }\end{array}$ & $\begin{array}{l}\text { Mometasone Spray } \\
\text { group } 100 \text { mcg } \\
(\mathrm{n}=36 \text { subjects })\end{array}$ & $\mathrm{P}$ \\
\hline \multicolumn{4}{|l|}{ Hour 0} \\
\hline No cough & $27(75 \%)$ & $29(80.6 \%)$ & \multirow{4}{*}{0.836} \\
\hline Cough lightly & $8(22.2 \%)$ & $6(16.7 \%)$ & \\
\hline Moderate cough & $1(2.8 \%)$ & $1(2.8 \%)$ & \\
\hline Severe cough & $0(0 \%)$ & $0(0 \%)$ & \\
\hline \multicolumn{4}{|l|}{ Hour 1} \\
\hline No cough & $32(88.9 \%)$ & $30(83.3 \%)$ & \multirow{4}{*}{0.556} \\
\hline Cough lightly & $4(11.1 \%)$ & $5(13.9 \%)$ & \\
\hline Moderate cough & $0(0 \%)$ & $1(2.8 \%)$ & \\
\hline Severe cough & $0(0 \%)$ & $0(0 \%)$ & \\
\hline \multicolumn{4}{|l|}{ Hour 6} \\
\hline No cough & $34(94.4 \%)$ & $35(97.2 \%)$ & \multirow{4}{*}{0.555} \\
\hline Cough lightly & $2(5.6 \%)$ & $1(2.8 \%)$ & \\
\hline Moderate cough & $0(0 \%)$ & $0(0 \%)$ & \\
\hline Severe cough & $0(0 \%)$ & $0(0 \%)$ & \\
\hline \multicolumn{4}{|l|}{ Hour 24} \\
\hline No cough & $36(100 \%)$ & $36(100 \%)$ & \multirow{4}{*}{1.000} \\
\hline Cough lightly & $0(0 \%)$ & $0(0 \%)$ & \\
\hline Moderate cough & $0(0 \%)$ & $0(0 \%)$ & \\
\hline Severe cough & $0(0 \%)$ & $0(0 \%)$ & \\
\hline
\end{tabular}

* Chi Square test, Pearson chi square; $\mathrm{p}$ is significant if $\mathrm{p}<0.05$

The incidence of hoarseness after endotracheal intubation obtained the results of statistical analysis of the probability value of hoarseness at $0,1,6$, and 24 hours, respectively $0.204 ; 0.233 ; 0.555$ and 1.000 $(\mathrm{p}>0.05)$ so it can be concluded that there is no significant difference in the incidence of hoarseness at 0 , 1,6 , and 24 hours between the two groups. (Table 5)

Table 5 Degree of Hoarseness

\begin{tabular}{lccc}
\hline Hoarseness degree & $\begin{array}{c}\text { Triamcinolone gel } \\
0.1 \% \text { group } \\
(\mathrm{n}=36 \text { subjects })\end{array}$ & $\begin{array}{c}\text { Mometasone Spray } \\
\text { group 100 mcg } \\
(\mathrm{n}=36 \text { subjects })\end{array}$ & $\mathrm{P}$ \\
\hline $\begin{array}{l}\text { Hour to 0 } \\
\text { Not hoarse }\end{array}$ & $29(80.6 \%)$ & $29(86.1 \%)$ & 0.204 \\
\hline
\end{tabular}




\section{Journal of Anesthesiology \& \\ Clinical Research}

\begin{tabular}{lccc}
\hline Light hoarseness & $4(11.1 \%)$ & $5(13.9 \%)$ & \\
Medium hoarse & $3(8.3 \%)$ & $0(0 \%)$ & \\
Heavy hoarse & $0(0 \%)$ & $0(0 \%)$ & \\
1st hour & & & \\
Not hoarse & $31(86.1 \%)$ & $30(83.3 \%)$ & \\
Light hoarseness & $5(13.9 \%)$ & $5(13.9 \%)$ & \\
Medium hoarse & $0(0 \%)$ & $1(2.8 \%)$ & \\
Heavy hoarse & $0(0 \%)$ & $0(0 \%)$ & \\
The 6 $6^{\text {th }}$ hour & & & \\
Not hoarse & $34(94.4 \%)$ & $35(97.2 \%)$ & \\
Light hoarseness & $2(5.6 \%)$ & $1(2.8 \%)$ & \\
Medium hoarse & $0(0 \%)$ & $0(0 \%)$ & \\
Heavy hoarse & $0(0 \%)$ & $0(0 \%)$ & \\
24 & & & \\
Not hour & $36(100 \%)$ & $36(100 \%)$ & \\
Light hoarse & $0(0 \%)$ & $0(0 \%)$ & \\
Medium hoarse & $0(0 \%)$ & $0(0 \%)$ & \\
Heavy hoarse & $0(0 \%)$ & $0(0 \%)$ & \\
\hline
\end{tabular}

* Chi Square test, Pearson chi square; $p$ is significant if $p<0.05$

\section{Discussion}

Sore throat, cough, and hoarseness or Post Operative Sore Throat (POST) is a complaint that is often experienced by patients after surgery under general anesthesia with endotracheal i ntubation. Although minor complications can lead to patient dissatisfaction and morbidity. ${ }^{2}$ Sarki et al said the incidence of sore throat, cough, and hoarseness was $80 \%, 43.3 \%$ 46.7\% without prophylaxis. ${ }^{10}$ Accordingto Mchardy et al the incidence of POST was $14.4 \%-50 \%^{2}$ whereas according to Ayoub et al. amounted to $21 \%-65 \% \cdot 6$ Of the 200 patients studied according to Edomwongi et al, the incidence of sore throat was $49 \%$, coughing $36 \%$ and hoarseness of 5\%. ${ }^{11}$ This was due to irritation and inflammation of the respiratory tract mucosa due to trauma. Lubrication is useful for minimizing mucosal injury by facilitating the entry of ETT into the airways.

Comparison of the effectiveness of giving $0.1 \%$ triamcinolone acetonide gel and $100 \mathrm{mcg}$ mometasone spray on the prevention of sore throat, cough, and hoarseness within 24 hours after endotracheal intubation. The incidence of cough, sore throat, and hoarseness in both groups was examined and then the Mc Nemar statistical test was performed. In the triamcinolone acetonide gel group 


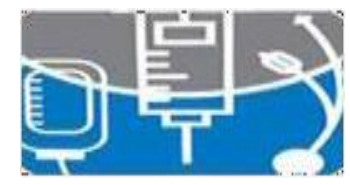

\section{Journal of Anesthesiology \& \\ Clinical Research}

$0.1 \%$ of all patients who experienced a cough, sore throat, and hoarseness all recovered within 24 hours of endotracheal intubation. In the $100 \mathrm{mcg}$ mometasone spray group, patients who experienced a sore throat, cough, and hoarseness recovered all 24 hours after endotracheal intubation. So there is no statistically significant difference (Table 2) between triamcinolone acetonide gel $0.1 \%$ and mometasone $100 \mathrm{mcg}$ to reduce sore throat. cough and hoarseness within 24 hours after endotracheal intubation $(\mathrm{p}=1.000 ; \mathrm{p}>$ 0.05). This shows that the two groups of drugs have no difference in effectiveness in reducing and preventing the incidence of POST after 24 hours after endotracheal intubation.

The result supports the study of Mchardy et al which states that large damage to the larynx and tracheal epithelium occurs as a result of insertion of tracheal intubation, especially in one hour after surgery and according to Vangipuram the peak of complaints occurs in the first 2-6 hours after extubation. of these complaining patients recovered spontaneously within 24 hours of endotrachealintubation. ${ }^{3,12}$

According to Selvaraj et al who compared steroid gel with mometasone spray, $100 \mathrm{mcg}$ found the incidence of sore throat $33.3 \%$ in the steroid gel group compared to $73.3 \%$ in the $100 \mathrm{mcg}$ mometasone spray group. ${ }^{23}$ According to Sarki et al. 36.7\%, 66.7\%; cough was 13.3\%, 26.7\%; and hoarseness was $23.3 \%, 30 \%$, for betamethasone compared to mometasone spray $100 \mathrm{mcg} .{ }^{10}$

The percentage of incidence of sore throat, cough, and hoarseness at 0 hours in the Zentika and Wendy study did not differ much ( $\pm 10 \%)$. Meanwhile, at 24 hours in Wendy's study, there were still incidents of sore throat, cough, and hoarseness. The incidence of sore throat, cough, and hoarseness in this study at the 0 hours was $38.9 \%, 25 \%$, and $19.4 \%$, respectively, and at the $24^{\text {th }}$ hour were $0 \%, 0 \%$, and 0 respectively. $\%$ when compared with Park et al's study with an incidence 24 hours after intubation of $18-22 \% .{ }^{13}$ It can be concluded that triamcinolone acetonide gel $0.1 \%$ and mometasone $100 \mathrm{mcg}$ are effective in reducing the incidence cough, sore throat, and hoarseness within 24 hours after intubation endotracheal. According to research by Wirdyani et al, mometasone spray is effective in reducing the incidence cough, sore throat, and hoarseness.

Sore throat after surgery is an inflammatory pain that occurs in about $90 \%$ of patients undergoing endotracheal intubation. Pharmacologically, the mechanism of this mometasone spray is inactivating the factor transcript of pro-inflammatory nuclear factor- $\kappa B(\mathrm{NF}-\mathrm{\kappa B})$ and activator protein-1 (AP-1) so that inflammation and pain do not occur. ${ }^{14}$ Dian et al's study, mometasone spray was more effective in reducing the incidence and degree of pain in the first hour after extubation compared to IV 


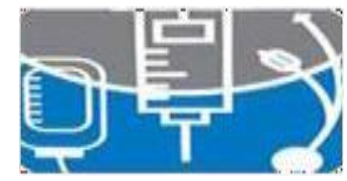

\section{Journal of Anesthesiology \& \\ Clinical Research}

dexamethasone. ${ }^{7}$ The results at the first hour were also confirmed by the study of Arunchai et al, stating that the incidence of sore throat after surgery in the mometasone group spray at the 1st hour was $40 \%$ compared to the saline group at $75 \%$.In Dian et al's study, mometasone spray is a moderate potency corticosteroid with a mechanism of action as a local anti-inflammatory, reducing capillary permeability and mucus production, causing vasoconstriction of the airway mucosa. The study of Freiri et al concluded that the clinical effect of mometasone spray in patients with allergic rhinitis consists of 2 phases, namely reducing the histamine level in nasal secretions (early phase response) which is seen within 30 minutes after administration and decreasing IL-6, IL-8, and eosinophils. during the slow phase response. The results of this study support previous studies that mometasone spray $100 \mathrm{mcg}$ are effective in reducing the incidence of sore throat at the 1 st hour. Whereas at $-0,6$ th, and 24 th hours, the results obtained are $p>0$,

The degree of cough between the two groups, the incidence of cough after endotracheal intubation, obtained a statistical analysis of the probability value of sore throat at $0,1,6$, and 24 hours, respectively $0.836 ; 0.556 ; 0.555$ and $1,000(\mathrm{p}>0.05)$ so that it can be concluded that there is no difference in the incidence of cough at $0,1,6$, and 24 hours between the two groups. The incidence of cough at 6,24 hours in the triamcinolone acetonide gel $0.1 \%$ and mometasone $100 \mathrm{mcg}$ groups was $5.6 \%$ and $2.8 \%$, respectively, indicating the effectiveness of these drugs in reducing cough. So it was concluded that there was no significant difference between the two groups in reducing the incidence of cough in the first 24 hours postextubation. Sore throat, coughing and hoarseness due to intubation are three things that are related to the location of the trauma,

The cough reflex is innervated by primary vagal afferent nerves such as bronchopulmonary rapidly adapting receptors (RAR) and bronchopulmonary $C$ fibers which are triggered by mechanical stimulation and the presence of deformities of the airway epithelium such as mucus and smooth muscle contraction. These reflexes are in the larynx, trachea, and carina. RAR is very sensitive to histamine mediators, bradykinin, prostaglandins, 5-hydroxytryptamine, capsaicin, tachykinin which is stimulated when there is trauma to the airway resulting in smooth muscle contraction, vasodilation, and edema. Inflammatory reactions can be treated with corticosteroid drugs such as triamcinolone acetonide. ${ }^{16}$

Muscles that play a role in the cough reflex include the laryngeal abductor muscles on the posterior cricoarytenoid and adductor muscles such as the thyroarytenoid and arytenoid. Local anesthetics such as lidocaine can block coughing as an antitussive by inhibiting neural sensory activity but their use is controversial because of their irritability. 


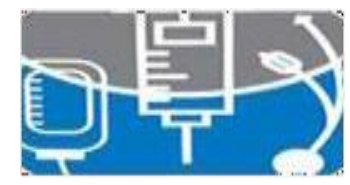

\section{Journal of Anesthesiology \& \\ Clinical Research}

The degree of hoarseness between the two groups, the incidence of hoarseness due to endotracheal intubation, obtained a statistical analysis of the probability value of hoarseness at $0,1,6$, and 24 hours, respectively $0.204 ; 0.223 ; 0.555$ and $1,000(\mathrm{p}>0.05)$ so that it can be concluded that there is no difference in the incidence of hoarseness at $0,1,6$, and 24 hours between the two groups. The percentage of sore throat, cough, and hoarseness after 24 hours post-extubation in the $0.1 \%$ triamcinolone acetonide gel group and $100 \mathrm{mcg}$ mometasone spray was almost $0 \%$. From tables 3, 4, and 5 the comparison of sore throat, cough, and hoarseness at hours 0,1,6, and 24 hours after endotracheal intubation between the two groups in percentage, the incidence of cough, sore throat, and hoarseness of the triamcinolone acetonide gel group 0 , $1 \%$ was always greater but not significantly different from the $100 \mathrm{mcg}$ mometasone spray group. This is due to reduced inflammation and edema because the application of local steroids reduces the inflammatory mediator production, by inhibiting phospholipase A2 and cyclooxygenase 2 during inflammation resulting in effective inhibition of inflammatory or ulcerative lesions in the mucosa.

\section{Conclusion}

There was no significant difference in the effectiveness of mometasone spray $100 \mathrm{mcg}$ with $0.1 \%$ triamcinolone acetonide gel against sore throat, cough, and hoarseness within 24 hours of endotracheal intubation. Comparison of the effectiveness of mometasone spray $100 \mathrm{mcg}$ and triamcinolone acetonide gel $0.1 \%$ in reducing the incidence of sore throat after endotracheal intubation at 1 hour, mometasone spray $100 \mathrm{mcg}$ was more effective than triamcinolone acetonide gel $0.1 \%$ statistically $\mathrm{P}=0.039(\mathrm{P}$ $<0.05$ ), while at 0,6 and 24 hours there was no significant difference, with each statistical value of $\mathrm{p}=$ $0.543 ; 0.643$; and 1,000 (P> 0.05). Comparison of the effectiveness of mometasone spray $100 \mathrm{mcg}$ and triamcinolone acetonide gel $0.1 \%$ in reducing the incidence of cough after endotracheal intubation was statistically no significant difference at $0,1,6$ and 24 hours with p-value $=0.836 ; 0.556 ; 0.555 ;$ and 1,000 $(\mathrm{P}>0.05)$. Comparison of the effectiveness of mometasone spray $100 \mathrm{mcg}$ and triamcinolone acetonide gel $0.1 \%$ in reducing the incidence of hoarseness in 24 hours after endotracheal intubation there was no statistically significant difference at $0,1,6$, and 24 hours, respectively. each p-value $=0.204 ; 0.233$; $0.555 ;$ and $1,000(\mathrm{p}>0.05)$.

Thus, it is recommended that triamcinolone acetonide gel $0.1 \%$ and mometasone $100 \mathrm{mcg}$ can be used before endotracheal intubation procedure to prevent and reduce the incidence of sore throat, cough, and hoarseness within 24 hours of endotracheal intubation. This research can be continued by examining 


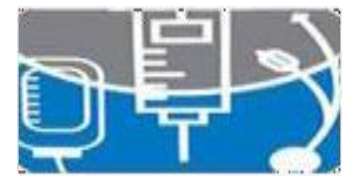

\section{Journal of Anesthesiology \& \\ Clinical Research}

the comparison of $0.1 \%$ triamcinolone acetonide gel and $100 \mathrm{mcg}$ mometasone spray in reducing sore throat with endotracheal intubation technique.

\section{References}

1. Baloch RN, Jakhrani NK, Lal A, Mehmood N. Role of dexamethasone for prevention of postextubation airway obstruction in critically ill adult patients. J Surg Pakistan.2010; 15 (1): 3-8.

2. Orandi, Orandi A, Najafi A, Hajimohammadi F, Soleimani S, Zahabi S. Post intubation sore throat and menstruation cycles. Anesth Pain Med. 2013; 3 (2): 243-49.

3. Narimani M, Mehdi SA, Gholami F, Ansari L, Arsyafar M, Shabbazi F. The effect of betamethasone gel and mometasone $100 \mathrm{mcg}$ jelly applied over tracheal tube cuff on postoperative sore throat, cough, and hoarseness. Perian Nurs. 2016; 31 (4): 298-302.

4. Mafiana R, Maas EM, Theodorus, Wijaya W. Comparison of efficacy between triamcinolone gel $0.1 \%$ and lidocaine gel $2 \%$ applied over tracheal tube to reduce postoperative sore throat, cough and hoarseness after general anesthesia. IJHSR. 2017; 12 (7): 6-15.

5. McHardy FE, Chung F. Postoperative sore throat: cause, prevention, and treatment. Anesth. $1999 ; 54$ (1): 444-53.

6. Ayoub MC, Ghobashy A, Koch ME, McGrimley A, Pascale V, Qadir S, et al. Widespread application of topical steroid to decrease sore throat, hoarseness, and cough after tracheal intubation. Anesth Analg. 1998; 87 (1): 714-6.

7. Wirdiyana D, Wahyudi, Achmad R. Comparison of the effectiveness of intravenous mometasone furoate and dexamethasone spray in reducing sore throat after surgery in endotracheal intubation general anesthesia. JAI. 2013; 5 (3): 159.

8. Wijaya AA, Garditya R, Marsaban HMA, Heriwardito A. Comparison of the use of topical triamcinolone acetonide with intravenous dexamethasone in reducing the incidence of postoperative sore throat. J Anesth Perioper. 2015; 3 (2): 117-22.

9. Wibowo A, Soenarjo, Hendriarto HS. Comparison of the use of triamcinolone acetonide and watersoluble gel in the endotracheal tube to the incidence of sore throat. JAI. 2014; 6 (3): 173.

10. Myron Z, Kosoglou T, Hubbel J. Mometasone furoate nasal spray a review of safety and systemic effects. Drug Saf. 2007; 30 (4):317-26.

11. Butterworth IV JF, Mackey DC, Wasnick JD. Airway management. In: Morgan \& Mikhail's clinical 


\section{Journal of Anesthestology \& \\ Clinical Research}

anesthesiology. 5th Ed. New York: McGraw Hill Education, LLC 2013: p. 309-41.

12. Paula BF. The relationship between preintubation mometasone $100 \mathrm{mcg}$ and postanesthesia sore throat. AANS. 1992; 6 (2): 374-78.

13. Maruyama K, Sakai H, Miyazawa H, Toda N, Linuma Y, Mochizuki N, et al. Sore throat and hoarseness after total intravenous anesthesia. Br J Anaesth. 2004; 92 (4): 541-3.

14. Günther AH. Pharmacokinetic/pharmacodynamic profile mometasone furoate nasal spray: potential effects on clinical safety. J clinthera. 2008; 5 (1): 149-291.

15. Sidhu G, Charles V. Triamcinolone. In: stat pearls treasure island (FL). Stat Pearls Publishing. 2020; 3-15.

16. Park SY, Kim SH, Lee SJ, Chae WS, Jin HC, Lee JS, et al. Application of triamcinolone acetonide paste to the endotracheal tube reduces postoperative sore throat: a randomized controlled trial. Can J Anesth. 2011; 58 (1): 436-42.51-4 